\title{
COMPREHENSIVE RADIOCARBON ANALYSIS OF BENZENE POLYCARBOXYLIC ACIDS (BPCAS) DERIVED FROM PYROGENIC CARBON IN ENVIRONMENTAL SAMPLES
}

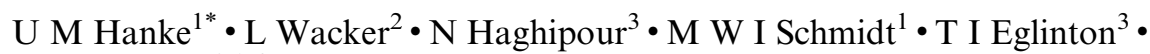 \\ C P McIntyre $2,3,4$
}

\author{
${ }^{1}$ Department of Geography, University of Zurich, Switzerland. \\ ${ }^{2}$ Laboratory of Ion Beam Physics, ETH Zurich, Switzerland. \\ ${ }^{3}$ Geological Institute, ETH Zurich, Switzerland. \\ ${ }^{4}$ Present address: AMS Laboratory, SUERC, East Kilbride, United Kingdom.
}

\begin{abstract}
Compound-specific radiocarbon analysis (CSRA) of benzene polycarboxylic acids (BPCAs) yields molecular-level, source-specific information necessary to constrain isotopic signatures of pyrogenic carbon. However, the purification of individual BPCAs requires a multistep procedure that typically results in only microgram quantities of the target analyte(s). Such small samples are highly susceptible to contamination by extraneous carbon, which needs to be minimized and carefully accounted for in order to yield accurate results. Here, we undertook comprehensive characterization and quantification of contamination associated with molecular radiocarbon $\left({ }^{14} \mathrm{C}\right)$ BPCA analyses through systematic processing of multiple authentic standards with both fossil and modern ${ }^{14} \mathrm{C}$ signatures at various concentrations. Using this approach, we precisely apportion the contribution of extraneous carbon with respect to the four implemented subprocedures. Assuming a constant source and quantity of extraneous carbon we correct and statistically evaluate uncertainties in resulting ${ }^{14} \mathrm{C}$ data. Subsequently, we examine the results of triplicate analyses of reference materials representing four different environmental matrices (sediment, soil, aerosol, riverine natural organic matter) and apportion their BPCA sources in terms of carbon residues derived from biomass or fossil fuel combustion. This comprehensive approach to CSRA facilitates retrieval of robust ${ }^{14} \mathrm{C}$ data, with application in environmental studies of the continuum of pyrogenic carbon.
\end{abstract}

KEYWORDS: BPCA, constant contamination, extraneous carbon, pyrogenic carbon, radiocarbon.

\section{INTRODUCTION}

The incomplete combustion of biomass and fossil fuels generates solid pyrogenic carbon (PyC) residues, which occur ubiquitously in the environment (Bird et al. 2015). Investigations of these products of incomplete combustion are particularly challenging in complex matrices due to a large variety of possible structural configurations of condensed aromatic compounds (Bird et al. 2015; Blumer 1976; Hedges et al. 2000). In addition to conventional methods that trace PyC on a bulk level (Gustafsson et al. 2001; Masiello et al. 2002; Meredith et al. 2012), specific polycyclic aromatic hydrocarbons (PAHs) and benzene polycarboxylic acids (BPCAs) can serve as molecular-level tracers of combustion residues (Blumer and Youngblood 1975; Glaser et al. 1998; Lima et al. 2005). Recently, we have shown that combined analysis of the abundances and distributions of both PAHs and BPCAs yields a more comprehensive view of the continuum of combustion residues occurring in environmental matrices (Hanke et al. 2016). It follows that the addition of corresponding ${ }^{14} \mathrm{C}$ signatures could greatly enhance our understanding of the origin of PyC accumulating in the environment. Radiocarbon $\left({ }^{14} \mathrm{C}\right)$ analyses of combustion products in environmental samples have the unique ability of apportioning sources of PyC to either biomass or fossil fuel combustion (Currie and Murphy 1977). However, the preparation of microgram quantities of sample material for ${ }^{14} \mathrm{C}$ analysis at the molecular level requires an extended chemical scheme and careful attention in order to minimize the addition of extraneous carbon prior to isotopic measurement.

BPCA molecular markers are produced by the oxidative chemical degradation of combustion residues (charred biomass) and condensates (soot-like structures) (Glaser et al. 1998; Roth et al. 2012).

\footnotetext{
*Corresponding author. Email: umhanke@googlemail.com.
} 
The BPCAs are composed of benzene rings with a varying number of carboxylic acid groups (Glaser et al. 1998). The method was originally developed for quantitative gas chromatographic (GC) measurement of BPCAs as their corresponding methyl ester derivatives (Glaser et al. 1998), this GC-based has subsequently been extended with a focus on compound-specific ${ }^{14} \mathrm{C}$ analysis (CSRA) of BPCAs (Ziolkowski and Druffel 2009; Coppola et al. 2013). In these latter studies, BPCAs were isolated via preparative capillary gas chromatography (PCGC) and subsequently graphitized for accelerator mass spectrometry (AMS) measurements. More recently, the BPCA analysis method has been adapted for liquid chromatography (LC) (Dittmar 2008; Schneider et al. 2011). This LC-based method allows for preparative isolation of individual BPCAs for isotopic analysis without derivatization prior to chromatographic separation (Gierga et al. 2014; Wiedemeier et al. 2016).

Advances in AMS technology now enable ${ }^{14} \mathrm{C}$ measurements of carbon dioxide gas at natural abundance levels on an ultra-microscale (2-100 $\mu$ g C) (Fahrni et al. 2013; Wacker et al. 2013). Direct measurements of $\mathrm{CO}_{2}$ supersede and negate the additional steps required for graphitization, albeit at the expense of precision. Recently, Lang and collaborators have developed a method based on wet chemical oxidation (WCO) for ${ }^{14} \mathrm{C}$ analysis of dissolved organic carbon (Lang et al. 2013, 2016). Compared with conventional approaches, such as those employing ultraviolet radiation (Armstrong et al. 1966; Beaupré et al. 2007), closed-tube combustion with cupric oxide (Boutton et al. 1983; Mann et al. 2015), or oxidation in the presence of permanganate (Leonard et al. 2013), the WCO method serves as a simple and effective approach that increases sample throughput and reduces costs. It is especially well suited to CSRA of water-soluble carbon compounds with low volatility. It has recently been demonstrated that BPCAs can be purified using preparative $\mathrm{LC}\left(\mathrm{LC}_{\text {prep }}\right)$, then oxidized via $\mathrm{WCO}$ and measured for ${ }^{14} \mathrm{C}$ using a gas ion source-equipped AMS (Gierga et al. 2014). The integration of multiple process standards with minimal additional effort introduces a new level of blank assessment that can greatly improve the quality of small-scale ${ }^{14} \mathrm{C}$ data.

Preparative chromatographic purification of individual compounds commonly yields less than $50 \mu \mathrm{g} \mathrm{C}$, thus molecular-level ${ }^{14} \mathrm{C}$ techniques are prone to extraneous carbon $(\mathrm{McNichol}$ and Aluwihare 2007) introduced during chemical pretreatment, purification and combustion steps. The smaller the sample sizes are, the higher the impact of extraneous carbon, particularly at the microgram scale level (5-25 $\mu$ g) (Kirner et al. 1995; Shah and Pearson 2007; Santos et al. 2010). To obtain accurate results, a careful assessment and correction of CSRA data is required, this is most readily achieved using the model of constant contamination, i.e. assuming a constant source and quantity of extraneous carbon. This represents a simple yet comprehensive approach to derive robust estimates of the true ${ }^{14} \mathrm{C}$ value of unknowns via mass balance and propagation of errors (Shah and Pearson 2007; Hwang and Druffel 2008; Ziolkowski and Druffel 2009; Santos et al. 2010; Wacker and Christl 2012). Contamination in sample materials comes from multiple sources and can carry fossil (e.g. petrochemical-derived solvents) as well as modern (e.g. ambient air) ${ }^{14} \mathrm{C}$ signatures. Thus, an assessment of extraneous carbon requires the use of ${ }^{14} \mathrm{C}$ standards with complementary ${ }^{14} \mathrm{C}_{\text {depleted }}$ and ${ }^{14} \mathrm{C}_{\text {modern }}$ signatures in order to enable the determination of actual mass and $\mathrm{F}^{14} \mathrm{C}$ of the total contamination (Mollenhauer and Rethemeyer 2009).

Assessing the extraneous carbon in multistep CSRA procedures and correcting the measured data for the total contamination is challenging yet crucial in order to yield refined molecular isotopic data that allows for a robust interpretation of the results. In the present study, we analyze a variety of process standards that encompass the full range of subprocedures. Additionally, the potential of the ${ }^{14} \mathrm{C}$-BPCAs methodology for real-world samples was tested using triplicate analysis of four different standard reference materials. The objectives of this study 
were to (1) quantify extraneous carbon in subprocedures of ${ }^{14} \mathrm{C}$-BPCA analyses, (2) allocate sources of extraneous carbon and propagate the errors, and (3) derive robust $\mathrm{F}^{14} \mathrm{C}$ values for BPCAs from four reference materials.

\section{MATERIALS AND METHODS}

\section{Overview}

The methodology used for BPCAs compound-specific isotopic analyses has been described and visually presented in detail elsewhere (Wiedemeier et al. 2016). Here, the focus is the characterization of the subprocedures; an overview of the steps and standard materials is given below and in Table 1. Each subprocedure uses a pair of ${ }^{14} \mathrm{C}$-modern and ${ }^{14} \mathrm{C}$-depleted materials (Table S1). For the entire procedure, we used chromatography-grade solvents and glassware that had recently $(<48 \mathrm{hr})$ been precombusted $\left(5 \mathrm{hr}, 500^{\circ} \mathrm{C}\right)$.

\section{Chemical Pretreatment: PyC Oxidation and BPCA Extraction}

The archeological (MA) and laboratory (W450) model charcoals are described in a previous study (Gierga et al. 2014). The archeological charcoal was found in pyroclastic deposits at Maninjau, Sumatra (Alloway et al. 2004) and had an $\mathrm{F}^{14} \mathrm{C}=0.003 \pm 0.001$ (ETH-50456) whereas the laboratory charcoal was obtained from the pyrolysis of chestnut woodchips under controlled conditions in the laboratory (Hammes et al. 2006) and had an $\mathrm{F}^{14} \mathrm{C}=1.149 \pm 0.004$ (ETH-50457). For both samples, bulk ${ }^{14} \mathrm{C}$ values were determined after acid-base-acid pretreatment ahead of the analysis to remove extraneous organic matter (Gierga et al. 2014).

An initial mass of model charcoals was back-calculated from previous data, targeting concentrations of $100 \pm 30 \mu \mathrm{g} \mathrm{C} \mathrm{mL}^{-1}$ (per vial) for the sum of $(1,2,3,4,5)$ - and $(1,2,3,4,5,6)$-benzene polycarboxylic acids. Weighed sample masses were heated with $2 \mathrm{~mL} \mathrm{HNO}_{3}(65 \%)$ in Teflon pressure chambers at $170^{\circ} \mathrm{C}$ for $8 \mathrm{hr}$. After a vacuum filtration using glass syringes $(6 \mathrm{~mL})$ and a glass fiber filter (Chromabond $® 0.7 \mu \mathrm{m}$ mesh size) an aliquot (40\%) was pipetted onto a cation exchange resin (Dowex ${ }^{\circledR}$ 50WX8) and then further cleaned by solid phase extraction (Discovery® DSC-18, $500 \mathrm{mg}$ tubes) before being transferred into analytical vials with $1 \mathrm{~mL}$ ultrapure water (Milli-Q® Advantage A10, $\leq 3$ ppb TOC).

Table 1 BPCA ${ }^{14} \mathrm{C}$ subprocedures including the type and range of different process standards and always consisting of both a ${ }^{14} \mathrm{C}$ depleted and modern material.

\begin{tabular}{|c|c|c|c|c|c|}
\hline $\begin{array}{l}\text { Sub- } \\
\text { procedures }\end{array}$ & Work steps & $\begin{array}{l}\text { Model } \\
\text { Charcoals } \\
\text { Geological } \\
\text { samples }\end{array}$ & $\begin{array}{l}\text { Model } \\
\text { BPCAs } \\
\text { Pure } \\
\text { compounds }\end{array}$ & $\begin{array}{l}\text { Sucrose and } \\
\text { Phthalic acid } \\
\text { Pure } \\
\text { compounds }\end{array}$ & $\begin{array}{l}\text { HOxII* and } \\
\text { ancient } \mathrm{CO}_{2} \\
\text { Diluted in } \\
\mathrm{He}\end{array}$ \\
\hline $\begin{array}{l}\text { Chemical } \\
\text { pretreatment }\end{array}$ & $\begin{array}{l}\text { Oxidative degradation of } \\
\text { condensed aromatic } \\
\text { structures }\end{array}$ & $\checkmark$ & $x$ & $x$ & $x$ \\
\hline Purification & $\begin{array}{l}\text { Isolation of compounds using } \\
\text { preparative LC }\end{array}$ & $\checkmark$ & $\checkmark$ & $x$ & $x$ \\
\hline $\begin{array}{l}\text { Wet chemical } \\
\text { oxidation }\end{array}$ & $\begin{array}{l}\text { Closed tube combustion with } \\
\text { sodium persulfate }\end{array}$ & $\checkmark$ & $\checkmark$ & $\checkmark$ & $x$ \\
\hline Measurement & $\begin{array}{l}\text { Gas ion-source equipped } \\
\text { AMS }\end{array}$ & $\checkmark$ & $\checkmark$ & $\checkmark$ & $\checkmark$ \\
\hline
\end{tabular}

*NIST SRM4990C. 


\section{Purification: Preparative Liquid Chromatography ( $\left.L C_{\text {prep }}\right)$}

Commercially available (1,2,3)-, (1,2,4)-, (1,2,4,5)-, (1,2,3,4,5)- and $(1,2,3,4,5,6)$-benzene polycarboxylic acid ( $\geq 98 \%$, Fluka and Aldrich) were used for the quantification of BPCAs in external standard solutions. These five pure BPCA compounds each had bulk ${ }^{14} \mathrm{C}$ values of $\mathrm{F}^{14} \mathrm{C} \leq 0.0008$ (ETH-57051 to 57055). For the modern counterpart, we used $(1,2,4)$-benzene polycarboxylic acid ( $\geq 98 \%$ ) prepared by custom synthesis (Chempur, Germany) with a bulk $\mathrm{F}^{14} \mathrm{C}=1.0422 \pm 0.0035$ (ETH-62938). Solutions of $200 \mu \mathrm{g} \mathrm{mL} \mathrm{m}^{-1}$ BPCAs in ultrapure water were equivalent to an ideal concentration of BPCAs in environmental samples aiming at yields of $30 \mu \mathrm{g} \mathrm{C}$ in purified fractions.

The $\mathrm{LC}_{\text {prep }}$ method for $\mathrm{BPCA}{ }^{14} \mathrm{C}$ had a total runtime of $30 \mathrm{~min}$, using a reversed phase analytical $\mathrm{C}-18$ column (Agilent, $2.7 \mu \mathrm{m})$ with two mobile phases: ultrapure water $\left(1.7 \% \mathrm{H}_{3} \mathrm{PO}_{4}\right)$ and acetonitrile ( $\geq 99.98 \%$, Scharlau, $\mathrm{F}^{14} \mathrm{C}<0.004$, ETH-74445). The elution times for BPCAs varied from 5.98 to $19.05 \mathrm{~min}$ depending on their polarity and structural features. Target compounds included either individual BPCA or combined BPCAs consisting of $(1,2,3,4,5,6)$-BPCA and $(1,2,3,4,5)$ BPCA for all environmental samples. After quantifying the respective compounds in solution $\left(1 \mu \mathrm{L}\right.$ inj.-vol. $\left.{ }^{-1}\right)$ using a diode array detector $(60 \mathrm{~mm}$ path length) the injection volume ( 1 to $20 \mu \mathrm{L} \mathrm{inj.}^{-1}$ ) was adjusted to equal $1 \mu \mathrm{g} \mathrm{C} \mathrm{BPCAs}{ }^{-1}$ at this level baseline separation was maintained. All BPCAs were collected in separate vials $(\leq 6 \mathrm{~mL})$ in repetitive runs and the fractions were placed on a heating plate $\left(\sim 70^{\circ} \mathrm{C}\right)$ under a gentle ultrapure nitrogen stream to evaporate the solvent for $3 \mathrm{hr}$. Subsequently, samples were stored in screw-cap vials with Teflon seals in the refrigerator until the next analytical step. We also collected blank eluents with a time window immediately preceding the target BPCA. The time window was $0.3 \mathrm{~min}$ for $(1,2,3,4,5,6)$-BPCA and $0.24 \mathrm{~min}$ for all the other BPCAs. Blanks were spiked with either sucrose or phthalic acid in concentrations of $15,25,40 \mu \mathrm{g}$ C prior to the wet chemical oxidation (WCO) step.

\section{Wet Chemical Oxidation}

The WCO procedure was performed according to Lang et al. (2013). Standards of phthalic acid $(\geq 99.5 \%$, Sigma-Aldrich) and sucrose $(\geq 99.5 \%$, Sigma) were dissolved in ultrapure water at a concentration of $2 \mu \mathrm{M}$ and $1.5 \mu \mathrm{M}$ respectively. The bulk ${ }^{14} \mathrm{C}$ values were $\mathrm{F}^{14} \mathrm{C} \leq 0.0008$ (ETH-57049) for phthalic acid and $\mathrm{F}^{14} \mathrm{C}=1.149 \pm 0.0048$ (ETH-57050) for sucrose. The standard solutions were prepared with the identical ultrapure water we had used for the preparation of the oxidant on the same day.

The WCO procedure converts BPCAs to carbon dioxide $\left(\mathrm{CO}_{2}\right)$, which then can directly be measured for ${ }^{14} \mathrm{C}$ using a gas ion source-equipped AMS (Lang et al. 2013). About $30 \mu \mathrm{g} \mathrm{C}$ sample ${ }^{-1}$ and $5 \mathrm{~mL}$ of purified sodium persulfate solution were transferred into $12 \mathrm{~mL}$ gas-tight borosilicate Exetainer vials with butyl rubber septum (Labco, UK) using acidified ultrapure water. The screwcapped vials were then purged with ultra high purity helium at $100 \mathrm{~mL} \mathrm{~min}^{-1}$ for $8 \mathrm{~min}$. Oxidation of the samples is achieved by placing the vials in a heating block at $95^{\circ} \mathrm{C}$ for $1 \mathrm{hr}$ (Lang et al. 2016).

\section{Measurement: Gas Ion Source AMS}

Gaseous samples were measured with a MIni CArbon DAting System (MICADAS, Ionplus, Switzerland) AMS fitted via a carbonate handling system modified with a needle for sparging solutions (Fahrni et al. 2013; Wacker et al. 2013). Briefly, sample $\mathrm{CO}_{2}(10-100 \mu \mathrm{g}$ C) was sparged from the solution in septa-sealed vials onto a zeolite molecular sieve trap. The $\mathrm{CO}_{2}$ gas was subsequently thermally desorbed and transferred to a gas-tight syringe with helium, then slowly injected into the gas-accepting ion source of the AMS at a constant rate (Lang et al. 2016). The measurement time was set to a maximum of $8 \mathrm{~min}$ in order to attain a precision of 
better than $1 \%$ on modern standard. The measured background was better than $44,000{ }^{14} \mathrm{C}$ yr. AMS data were normalized and background corrected with in-house standard gases prepared from Oxalic acid II (NIST SRM 4990C, $\mathrm{F}^{14} \mathrm{C}=1.3407$; ETH-54368) and ancient carbon dioxide $\left(\mathrm{F}^{14} \mathrm{C} \leq 0.0041\right.$; ETH-41218). Gas samples $(10-60 \mu \mathrm{g} \mathrm{C})$ were measured in a single sequence of in total 64 AMS measurements.

\section{Statistical Evaluation of Radiocarbon Data}

Data were processed using BATS software (Wacker et al. 2010) and the measured ${ }^{14} \mathrm{C} /{ }^{12} \mathrm{C}$ ratios are reported as $\mathrm{F}^{14} \mathrm{C}$ according to Reimer et al. (2004). To extract the $\mathrm{F}^{14} \mathrm{C}$ of samples $\left(\mathrm{F}^{14} \mathrm{C}_{\mathrm{S}}\right)$ from the measured AMS data $\left(\mathrm{F}^{14} \mathrm{C}_{\mathrm{M}}\right)$, we applied the model of constant contamination represented by Equation (1)

$$
\mathrm{F}^{14} \mathrm{C}_{\mathrm{S}}=\frac{\mathrm{F}^{14} \mathrm{C}_{\mathrm{M}}{ }^{*} \mathrm{~m}_{\mathrm{M}}-\mathrm{F}^{14} \mathrm{C}_{\mathrm{C}}{ }^{*} \mathrm{~m}_{\mathrm{C}}}{\mathrm{m}_{\mathrm{M}}-\mathrm{m}_{\mathrm{C}}}
$$

where $\mathrm{F}^{14} \mathrm{C}_{\mathrm{C}}$ is the contaminant $\mathrm{F}^{14} \mathrm{C}$, the total mass of the sample measured by the AMS $\left(\mathrm{m}_{\mathrm{M}}\right)$ is the sum of the mass of the sample $\left(\mathrm{m}_{\mathrm{S}}\right)$ and the mass of the contaminant $\left(\mathrm{m}_{\mathrm{C}}\right)$ (Wacker and Christl 2012). The associated uncertainty $\left(\sigma \mathrm{F}^{14} \mathrm{C}_{\mathrm{S}}\right)$ of $\mathrm{F}^{14} \mathrm{C}_{\mathrm{S}}$ was calculated by propagation of respective errors according to Equation (2)

$$
\begin{aligned}
\sigma_{\mathrm{F}^{14} \mathrm{Cs}}^{2}= & {\left[\sigma_{\mathrm{m}_{\mathrm{C}}}\left(\frac{\mathrm{F}^{14} \mathrm{C}_{\mathrm{M}}{ }^{*} \mathrm{~m}_{\mathrm{M}}-\mathrm{F}^{14} \mathrm{C}_{\mathrm{C}}{ }^{*} \mathrm{~m}_{\mathrm{C}}}{\left(\mathrm{m}_{\mathrm{M}}-\mathrm{m}_{\mathrm{C}}\right)^{2}}\right)-\left(\frac{\mathrm{F}^{14} \mathrm{C}_{\mathrm{C}}}{\mathrm{m}_{\mathrm{M}}-\mathrm{m}_{\mathrm{C}}}\right)\right]^{2} } \\
& +\left[\sigma_{\mathrm{m}_{\mathrm{M}}}\left(\frac{\mathrm{F}^{14} \mathrm{C}_{\mathrm{M}}}{\mathrm{m}_{\mathrm{M}}-\mathrm{m}_{\mathrm{C}}}-\frac{\mathrm{F}^{14} \mathrm{C}_{\mathrm{M}}{ }^{*} \mathrm{~m}_{\mathrm{M}}-\mathrm{F}^{14} \mathrm{C}_{\mathrm{C}}{ }^{*} \mathrm{~m}_{\mathrm{C}}}{\left(\mathrm{m}_{\mathrm{M}}-\mathrm{m}_{\mathrm{C}}\right)^{2}}\right)\right]^{2} \\
& +\left[\sigma_{\mathrm{F}^{14} \mathrm{C}_{\mathrm{M}}} \frac{\mathrm{m}_{\mathrm{M}}}{\mathrm{m}_{\mathrm{M}}-\mathrm{m}_{\mathrm{C}}}\right]^{2}+\left[\sigma_{\mathrm{F}^{14} \mathrm{C}_{\mathrm{C}}} \frac{-\mathrm{m}_{\mathrm{C}}}{\mathrm{m}_{\mathrm{M}}-\mathrm{m}_{\mathrm{C}}}\right]^{2}
\end{aligned}
$$

In order to obtain $\mathrm{F}^{14} \mathrm{C}_{\mathrm{S}}$, it is necessary to first determine the contaminant $\mathrm{F}^{14} \mathrm{C}_{\mathrm{C}}$ and $\mathrm{m}_{\mathrm{C}}$. For this, we used multiple process standards of known $\mathrm{F}^{14} \mathrm{C}$ in concentrations that spanned the range of measured samples $(10-60 \mu \mathrm{g} \mathrm{C})$. Pairs of complementary ${ }^{14} \mathrm{C}$ standard materials, one ${ }^{14} \mathrm{C}$ depleted $\left(\mathrm{F}^{14} \mathrm{C}=0\right)$ and the other modern $\left(\mathrm{F}^{14} \mathrm{C} \geq 1\right)$, were used for evaluation of the contamination using an end-member approach. Different standards were used to assess the contamination of the different subprocedures used in sample preparation (Table 1).

The depleted and modern process standards were used to determine the modern and the dead contamination, respectively, of the sample.

$\mathrm{F}^{14} \mathrm{C}_{\mathrm{C}}$ is then

$$
\mathrm{F}^{14} \mathrm{C}_{\mathrm{C}}=\frac{\mathrm{F}^{14} \mathrm{C}_{\mathrm{C}_{\text {modern }}}{ }^{*} \mathrm{~m}_{\mathrm{C}_{\text {modern }}}}{\mathrm{m}_{\mathrm{C}_{\text {depleted }}}+\mathrm{m}_{\mathrm{C}_{\text {modern }}}}
$$

and $\mathrm{m}_{\mathrm{C}}$

$$
\mathrm{m}_{\mathrm{C}}=\mathrm{m}_{\mathrm{C}_{\text {depleted }}}+\mathrm{m}_{\mathrm{C}_{\text {modern }}}
$$

for the respective subprocedures. The mass of ${ }^{14} \mathrm{C}$-depleted and modern contamination was determined by a fit (minimizing the chi-squares) to the measured standards. The amount 
of $\mathrm{m}_{\mathrm{C}}$, separated into ${ }^{14} \mathrm{C}$-depleted and modern components, was varied to evaluate the best fit of the modeled curves to the measured data. Reduced chi-squared statistics were then used to assess the statistical quality of the evaluation (Pearson's chi-square test). Subsequently the modern and fossil contamination was used to calculate $\mathrm{F}^{14} \mathrm{C}_{\mathrm{C}}$ (Equation 3 ) and the $\mathrm{m}_{\mathrm{C}}$ (Equation 4) for the different subprocedures. The uncertainties in the modeled $\sigma \mathrm{F}^{14} \mathrm{C}_{\mathrm{C}} \pm \sigma_{\mathrm{mc}}$ cannot be determined independently; we thus assigned a $10 \%$ uncertainty for each parameter as it accounts well for the observed scatter of the measured process standards. The proportional contribution of contamination for the individual steps of sample preparation was then calculated by subtraction. An example spreadsheet of calculations for the charcoal samples is given in the supplemental information.

\section{Environmental Samples: Reference Materials}

Four reference materials representing diverse yet common types of environmental samples were selected and analyzed for bulk ${ }^{14} \mathrm{C}$ and BPCA ${ }^{14} \mathrm{C}$. Marine sediment Standard Reference Material (SRM) 1941b and urban dust SRM 1649a were obtained from the U.S. National Institute of Standards and Technology (NIST) and full details are given in the certificate of analysis (NIST 2007; 2015). The chernozem soil black carbon reference material was obtained from University of Zurich. Further details are given in Hammes et al. (2008) and online at http://www.geo.uzh.ch/en/units/2b/Services/BC-material.htmL. Natural organic matter (NOM) from the Suwannee River $(2 \mathrm{R} 101 \mathrm{~N})$ was obtained from the International Humic Substances Society (IHSS). Samples were analyzed for bulk ${ }^{14} \mathrm{C}$ using conventional graphite preparation at the laboratory of ion beam physics, ETH Zürich. CSRA of BPCAs was performed in triplicate, with resulting data used to apportion fossil $\left(\mathrm{F}^{14} \mathrm{C}=0\right)$ and modern $\left(\mathrm{F}^{14} \mathrm{C} \sim 1\right)$ sources of combustion products according to Currie et al. (1989). To account for different possible modern sources we used two end members: $\mathrm{F}^{14} \mathrm{C}_{\text {contemporary, which is the year }}$ of sampling (annual production) and $\mathrm{F}^{14} \mathrm{C}_{\text {biomass }}$ integrating 30 years of biomass growth (perennial production) similar to $\mathrm{Xu}$ et al. (2012).

\section{RESULTS AND DISCUSSION}

Comprehensive characterization and quantification of extraneous carbon in small-scale ${ }^{14} \mathrm{C}$ analyses allow sample ${ }^{14} \mathrm{C}$ values to be accurately determined and facilitates robust data interpretation. Figure 1 illustrates the results of measured process standards $\left({ }^{14} \mathrm{C}\right.$ modern and depleted) for the three subprocedures-chemical pretreatment, purification, and WCO. The measured results on reference materials can be found in Table 2, including bulk $\mathrm{F}^{14} \mathrm{C}$, ${ }^{14} \mathrm{C}$-BPCA uncorrected (after normalization of MICADAS instrumental measurement uncertainty) and corrected values including the propagation of errors from chemical pretreatment, purification, WCO and AMS. Worthy of note is that after the preparative purification of target compounds, all samples were combusted on a single day $(\mathrm{n}=55)$ and then measured on the AMS in a single sequence the following day. The processed AMS data (BATS software, sequence: \#C160520UHG1) provided by ETH Zurich is included in the supporting information (Table S2).

\section{Constant Contamination}

In small-scale ${ }^{14} \mathrm{C}$ analyses, the total mass measured comprises the mass of the sample and the mass of the contaminant, the latter of which can be assessed via external process standards of known $\mathrm{F}^{14} \mathrm{C}$, as well as via spiked process blanks (Lang et al. 2016; Pearson et al. 1998; Ziolkowski and Druffel 2009). Encompassing the entire BPCA ${ }^{14} \mathrm{C}$ analysis, the process standard charcoals yield a constant contamination of $3.50 \pm 0.35 \mu \mathrm{g} \mathrm{C}$ and $0.443 \pm 0.044 \mathrm{~F}^{14} \mathrm{C}$. 
Mass [ $\mu \mathrm{g}]$

Mass [ $\mu \mathrm{g}]$
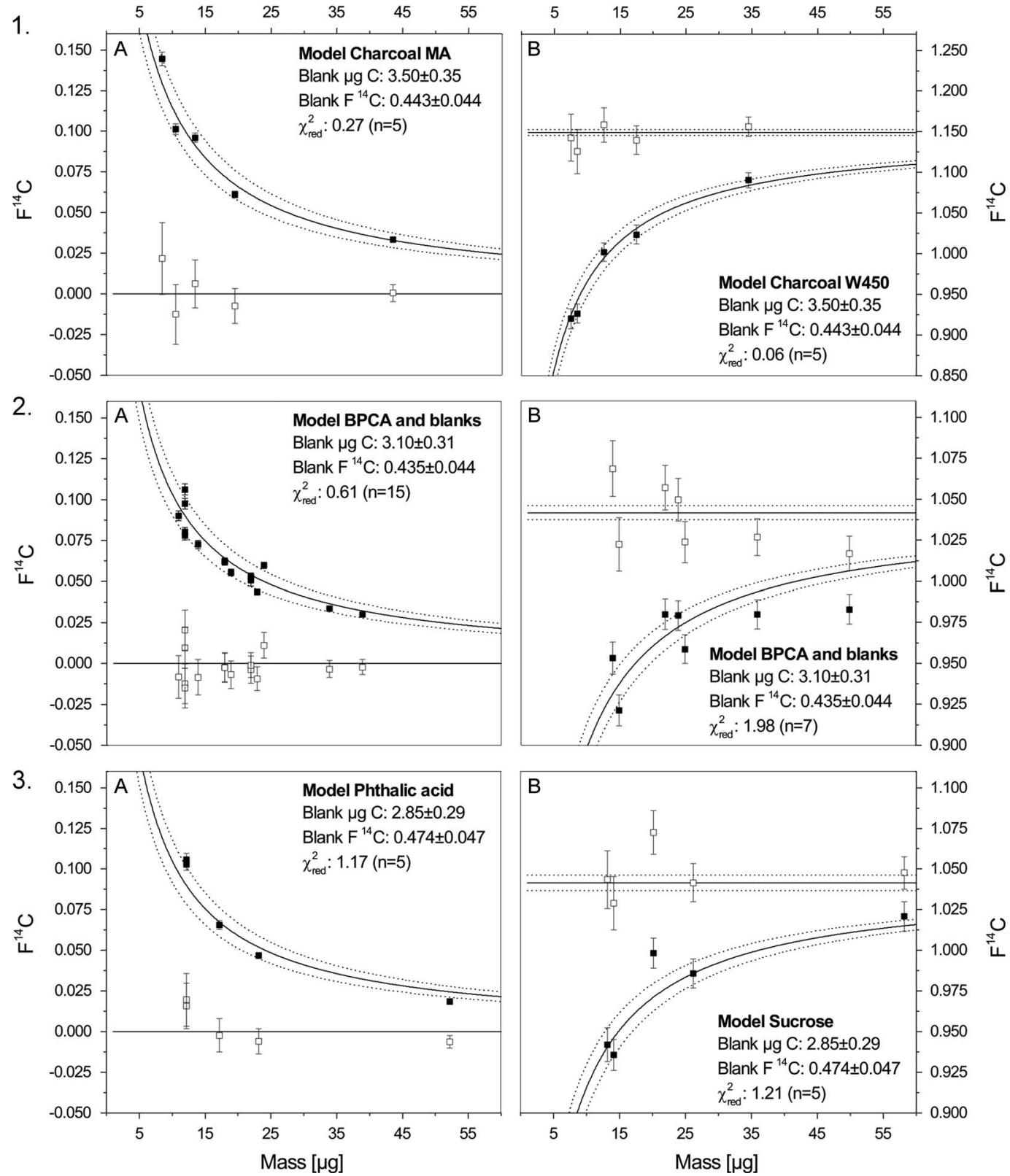

Figure 1 Measured AMS data are plotted as ${ }^{14} \mathrm{C}$ content $\left(\mathrm{F}^{14} \mathrm{C}\right)$ versus sample size $(\mu \mathrm{g} \mathrm{C})$ for measured process standards (solid black squares) for the different subprocedures with $A=F^{14} C$ depleted standards and $B=F^{14} C$ modern standards: 1. Chemical pretreatment (process standards that span the entire procedure), 2. Purification (preparative chromatography standards) and 3. Wet Chemical Oxidation (WCO standards). The solid curved lines with the 1-sigma error ranges (dotted) are the chi-square fitted curves. The open squares show the corrected $\mathrm{F}^{14} \mathrm{C}$ with propagated uncertainties that scatter around the known bulk $\mathrm{F}^{14} \mathrm{C}$ value of the standard materials (solid straight lines). 
Table 2 Results from bulk $\mathrm{F}^{14} \mathrm{C}$ and $\mathrm{BPCAs}{ }^{14} \mathrm{C}$ analysis for four different complex environmental matrices without $\left(\mathrm{F}^{14} \mathrm{C}_{\text {uncorrected }}\right)$ and with correction for the external contamination $\left(\mathrm{F}^{14} \mathrm{C}_{\text {corrected }}\right)$ using the model of constant contamination.

\begin{tabular}{|c|c|c|c|c|c|c|c|}
\hline \multirow[b]{2}{*}{ ETH \# } & \multirow[b]{2}{*}{ Name } & \multirow[b]{2}{*}{ Reference } & \multirow{2}{*}{$\begin{array}{l}\mathrm{TC} \\
{[\%]}\end{array}$} & \multirow{2}{*}{$\begin{array}{l}\text { Bulk } \\
\mathrm{F}^{14} \mathrm{C}\end{array}$} & \multicolumn{3}{|c|}{$\begin{array}{l}\text { Benzene polycarboxylic } \\
\text { acids (BPCA) }\end{array}$} \\
\hline & & & & & {$\left[\mathrm{g} \mathrm{kg}^{-1}\right]$} & $\mathrm{F}^{14} \mathrm{C}_{\text {uncorrected }}$ & $\mathrm{F}^{14} \mathrm{C}_{\text {corrected }}$ \\
\hline $68463-68465$ & $\begin{array}{l}\text { Organics in } \\
\text { marine sediment }\end{array}$ & NIST 1941b & 3.0 & $0.568 \pm 0.003^{*}$ & $1.39 \pm 0.02$ & $0.241 \pm 0.002$ & $0.217 \pm 0.009$ \\
\hline 68466-68468 & Soil chernozem & $\begin{array}{l}\text { University } \\
\text { of Zurich }\end{array}$ & 2.0 & $0.874 \pm 0.004 *$ & $2.09 \pm 0.02$ & $0.557 \pm 0.004$ & $0.574 \pm 0.008$ \\
\hline $68460-68462$ & Urban dust & NIST 1649a & 17.7 & $0.509 \pm 0.002 *$ & $9.76 \pm 0.10$ & $0.126 \pm 0.002$ & $0.088 \pm 0.009$ \\
\hline 68469-68471 & $\begin{array}{l}\text { Riverine natural } \\
\text { organic matter }\end{array}$ & IHSS & 50.7 & $1.057 \pm 0.005^{*}$ & $20.85 \pm 0.36$ & $0.950 \pm 0.005$ & $1.020 \pm 0.007$ \\
\hline
\end{tabular}

*Bulk $\mathrm{F}^{14} \mathrm{C}$ values refer to ETH\#: 67206-67209.

The model BPCAs and blanks (Purification and WCO) are slightly lower with $3.10 \pm 0.31 \mu \mathrm{g} \mathrm{C}$ and $0.435 \pm 0.044 \mathrm{~F}^{14} \mathrm{C}$ while the contamination for phthalic acid and sucrose (WCO) is $2.85 \pm 0.29 \mu \mathrm{g} \mathrm{C}$ and $0.474 \pm 0.047 \mathrm{~F}^{14} \mathrm{C}$.

A few studies have previously reported extraneous carbon in CSRA using either a different methodological setup or only certain subprocedures of multistep analyses. For example, Lang and collaborators reported a total contamination for the same $W C O$ procedure of $0.68 \pm 0.26$ to $1.05 \pm 0.23 \mu \mathrm{g} \mathrm{C}$ and $0.027 \pm 0.015$ to $0.107 \pm 0.051 \mathrm{~F}^{14} \mathrm{C}$ (Lang et al. 2016). The feasibility study by Gierga and collaborators that provides the foundation for the present approach assessed the uncertainties from AMS as well as WCO, found a contamination of $1.6 \pm 0.2 \mu \mathrm{g} C$ and $0.90 \pm 0.14 \mathrm{~F}^{14} \mathrm{C}$ (Gierga et al. 2014). Another study focused on purification of a different suite of target compounds, tetra-ether lipids, via $\mathrm{LC}_{\text {prep }}$ (with closed-tube combustion), found a contamination of $1.0 \pm 0.2 \mu \mathrm{g} \mathrm{C}$ (Shah and Pearson 2007). Contamination in CSRA has also been reported for PCGC (with vacuum line and graphitization) with $<1.0 \pm 0.5 \mu \mathrm{g}$ C for fatty acids and $<0.17 \mu \mathrm{g} C$ for phospholipid fatty acids and alkanes (Santos et al. 2010). In the conventional ${ }^{14} \mathrm{C}$-BPCA method using PCGC (with cupric oxide combustion and graphitization), the extraneous carbon has been estimated to be $2.0 \pm 1.0 \mu \mathrm{g} \mathrm{C}$ and $0.158 \pm 0.026 \mathrm{~F}^{14} \mathrm{C}$ in 2011 and $1.6 \pm 0.9 \mu \mathrm{g} \mathrm{C}$ and $0.067 \pm 0.025 \mathrm{~F}^{14} \mathrm{C}$ in 2012 (Coppola et al. 2013) demonstrating a good reproducibility of the method.

\section{Allocation of Constant Contamination to Subprocedures}

The multistep design of our approach allows the comprehensive assessment of extraneous carbon in CSRA and the quantitative attribution of contamination to individual subprocedures. As all process standards incrementally include one to three subprocedures, the partial contamination can be calculated backwards from the $W C O$ step. Here, the contamination by WCO accounts for $81 \%(2.85 \pm 0.29 \mu \mathrm{g} \mathrm{C})$ of total contamination carrying a ${ }^{14} \mathrm{C}$ signature of $0.474 \pm 0.047 \mathrm{~F}^{14} \mathrm{C}$. Additionally, the $\mathrm{LC}_{\text {prep }}$ adds $0.25 \pm 0.12 \mu \mathrm{g} \mathrm{C}\left(\mathrm{F}^{14} \mathrm{C}=\right.$ $0.0 \pm 0.5)$ indicating that the source of the contaminant is ${ }^{14} \mathrm{C}$ depleted and probably stems from the incomplete removal of LC mobile phase acetonitrile. The subprocedure chemical pretreatment adds $0.40 \pm 0.14 \mu \mathrm{g} \mathrm{C}\left(\mathrm{F}^{14} \mathrm{C}=0.50 \pm 0.25\right)$, suggesting that extensive sample transfers and exposure to ambient air may have introduced extraneous carbon from variable sources. Together, the chemical pretreatment and the purification procedures result in an accumulated contamination of $0.65 \pm 0.14 \mu \mathrm{g} C\left(\mathrm{~F}^{14} \mathrm{C}=0.31 \pm 0.06\right)$. The propagation 
of error calculations returned uncertainties of about 20 to $50 \%$, depending on the strength of the statistical fit of modeled and measured data. The measured data for the subprocedures $W C O$ and chemical pretreatment fall within the 1-sigma error range, whereas the purification procedure exhibits a slightly larger deviation in the modern standards (Figure 1). Nonetheless, it is evident that the vast majority of total contamination stems from the $W C O$ procedure.

In considering the origin of the $W C O$ contaminant, two possible sources may be taken into consideration - the purified oxidant sodium persulfate and the ultrapure water $\left(5 \mathrm{~mL} \mathrm{sample} \mathrm{L}^{-1}\right)$. A test measurement of the purified oxidant several days ahead of the AMS analysis sequence did not indicate any significant impurity. Thus we infer that the contamination likely originated from the water. About $2 \mathrm{~L}$ of MilliQ ${ }^{\circledR}$ water (TOC $\leq 3 \mathrm{ppb}$ ) was subsampled on the day of the analyses. The water treatment system was maintained in good condition, including use of fresh (10-week-old) MilliQ ${ }^{\circledR}$ cartridges Q-Guard®T2 and Quantum ${ }^{\circledR}$ TEX. However, the distilled source water feeding the ultra-purification device can vary in purity, even though the displayed TOC may suggest an excellent water quality ( $\sim 3 \mathrm{ppb}$ TOC). Further precautionary steps, such as UV oxidation of water immediately prior to use, are therefore recommended to minimize this potential source of contamination. Lang et al. (2016) showed that the contamination from WCO can be as low as $0.68 \mu \mathrm{g} \mathrm{C}$ which is at least consistent with blank values reported for the other combustion techniques and would result in a total contamination of $1.33 \mu \mathrm{g} \mathrm{C}$ if attained in this study. Additionally, this study used the same experimental setup as Lang et al. (2013) of $5 \mathrm{~mL}$ solvent (sample and oxidant in water) in $12 \mathrm{~mL}$ Exetainer vials yet, this could possibly be reduced to $3 \mathrm{~mL}$ solvent. This would ideally have lowered the contamination from WCO for $40 \%$. However, such changes to the protocol require test measurements on the gas ion sourceequipped AMS for revalidation.

\section{Application and Source Apportionment to Reference Materials}

Results for bulk and CSRA ${ }^{14} \mathrm{C}$ signatures and quantities of BPCAs for the four reference materials, representing different environmental settings and matrices, are given in Table 2. Triplicate BPCAs ${ }^{14} \mathrm{C}$ measurements on these standard materials were performed in order to test the applicability and reproducibility of the method. The average ${ }^{14} \mathrm{C}$ abundances in total carbon (TC) vary from $\mathrm{F}^{14} \mathrm{C}=0.509 \pm 0.002$ to $0.874 \pm 0.004$, implying that some proportion of TC in each sample is either of fossil origin or was pre-aged, thereby diluting the contemporary ${ }^{14} \mathrm{C}$ signatures at the time of deposition. In contrast, the riverine natural organic matter exhibits contemporary ${ }^{14} \mathrm{C}$ concentrations of $1.057 \mathrm{~F}^{14} \mathrm{C}$ (Suwannee River NOM, sampled via reverse osmosis in 2012).

BPCA quantification returned values of between 1.39 and $20.85 \mathrm{~g} \mathrm{~kg}^{-1}$ of sample, accounting for between 4.8 and $10.4 \%$ of TC. For CSRA, measured concentrations of $(1,2,3,4,5,6)$-BPCA and $(1,2,3,4,5)$-BPCA were between $78.1 \pm 6.4$ and $128.4 \pm 5.3 \mu \mathrm{g} \mathrm{CmL}^{-1}$. The masses of $\mathrm{BPCAs}{ }^{14} \mathrm{C}$ recovered from reference materials varied between 24 to $36 \mu \mathrm{g}$. The measured ${ }^{14} \mathrm{C}$ abundances of different BPCA ${ }^{14} \mathrm{C}$ encompassed almost the entire spectrum of natural abundance ${ }^{14} \mathrm{C}$ values, ranging from $0.088 \pm 0.009 \mathrm{~F}^{14} \mathrm{C}_{\text {corrected }}$ for atmospheric particulates to $1.020 \pm 0.007 \mathrm{~F}^{14} \mathrm{C}_{\text {corrected }}$ for the riverine NOM. The latter is indistinguishable from that of Coppola et al. (2015) who reported $1.02 \pm 0.02 \mathrm{~F}^{14} \mathrm{C}$ for the same material using a different molecular ${ }^{14} \mathrm{C}$ approach.

Combustion-derived carbon can be apportioned to fossil and contemporary sources by $\mathrm{F}^{14} \mathrm{C}$ measurements (Currie and Murphy 1977; Currie et al. 1989; Currie 2000; Szidat et al. 2006). 


\section{$1112 U$ M Hanke et al.}

In reference to the growth phase of biomass (May to August), we calculated the mean atmospheric $\mathrm{F}^{14} \mathrm{C}$ using the extended IntCal13 ${ }^{14} \mathrm{CO}_{2}$ concentration of the Northern Hemisphere (Levin and Kromer 2004; Levin et al. 2013). As trees integrate the atmospheric $\mathrm{F}^{14} \mathrm{C}$ over their period of growth (Lewis et al. 2004), we took a 30-year average prior to the sampling date in order to account for wood-derived combustion residues $\left(\mathrm{F}^{14} \mathrm{C}_{\text {biomass }}\right)$. PyC from annual biomass (e.g, grasses) constitute an additional BPCAs source, thus we also considered the atmospheric ${ }^{14} \mathrm{C}$ abundance at the year of sampling $\left(\mathrm{F}^{14} \mathrm{C}_{\text {contemporary }}\right.$ (Xu et al. 2012). Uncertainties include individual ${ }^{14} \mathrm{C}$ data as well as standard deviations from average atmospheric $\mathrm{F}^{14} \mathrm{C}$ values. Results of the NIST $1941 \mathrm{~b}$ (marine sediment) yield a $f_{\text {fossil }}$ of $82.9 \pm 2.8 \%$ for $\mathrm{F}^{14} \mathrm{C}_{\text {biomass }}$ and

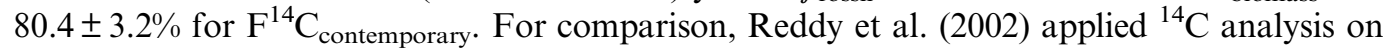
residues derived from the thermochemical oxidation (CTO-375) of environmental samples (Gustafsson and Gschwend 1997; Gustafsson et al. 2001) and found about $98.5-98.8 \% f_{\text {fossil }}$ for the predecessor NIST 1941a. BPCA ${ }^{14} \mathrm{C}$ analysis of NIST 1649a (urban dust) yields $f_{\text {fossil }}$ $93.4 \pm 2.6 \%$ for $\mathrm{F}^{14} \mathrm{C}_{\text {biomass }}$ and $93.5 \pm 2.6 \%$ for $\mathrm{F}^{14} \mathrm{C}_{\text {contemporary. Similar values were reported by }}$ Reddy et al. (2002) for CTO-375 with $f_{\text {fossil }}$ of $93.5-95.2 \%$ and by Currie et al. (2002) for chemical oxidation residues (dichromate method) with $f_{\text {fossil }} 88.7 \%$ as well as for thermal optical kinetic (TOK) procedure with $f_{\text {fossil }} 97.4 \%$ always referring to $\mathrm{F}^{14} \mathrm{C}_{\text {contemporary }}$. Source apportionment for riverine $\mathrm{NOM}(2 \mathrm{R} 101 \mathrm{~N})$ results in $f_{\text {fossil }}$ of $8.9 \pm 3.0 \%$ for $\mathrm{F}^{14} \mathrm{C}_{\text {biomass }}$ and $1.9 \pm 3.3 \%$ for $\mathrm{F}^{14} \mathrm{C}_{\text {contemporary }}$.

Radiocarbon analyses on soils have a great potential for the study of carbon turnover, yet time lags between assimilation and incorporation in soils as well as lateral and vertical spatial heterogeneity can challenge interpretations (Trumbore 2009; Van der Voort et al. 2016). We therefore chose not to attempt source apportionment on the chernozem soil due to the absence of sufficient age constraints on charred soil organic matter (Carcaillet 2001).

The corrected ${ }^{14} \mathrm{C}$-BPCA data compare well with the limited available literature data and lend support to the applicability of $\mathrm{PyC}$ source apportionment in different complex matrices using this particular method. Analyzed samples range from $\mathrm{F}^{14} \mathrm{C}<0.1$ to $\mathrm{F}^{14} \mathrm{C} \geq 1$. Environmental matrices from locations with a pronounced human (urban, industrial) influence contain combustion products of mainly fossil origin. In contrast, the Suwannee river catchment drains swamp areas with a high fire return frequency and thus yields modern ${ }^{14} \mathrm{C}$ signatures. The two different proportions calculated for atmospheric ${ }^{14} \mathrm{C}$ concentrations $\left(\mathrm{F}^{14} \mathrm{C}_{\text {biomass }}\right.$ and $\mathrm{F}^{14} \mathrm{C}_{\text {contemporary }}$ ) influence the fractional contribution of fossil carbon only to a less extent during this period of waning thermo-nuclear ("bomb") ${ }^{14} \mathrm{C}$ concentrations.

\section{Implications for Dating and Source Apportionment}

Molecular ${ }^{14} \mathrm{C}$ data on pyrogenic carbon provides an important window on the origin and dynamics of this important component of the global carbon cycle. By combining (1) comprehensive characterization and quantification of contamination associated with sample processing for small-scale ${ }^{14} \mathrm{C}$ analysis, (2) assessments of reproducibility through triplicate analyses of samples, a new level of confidence in CSRA has been achieved. Adopting the constant contamination approach to account for contamination associated with analysis of reference materials led to lower BPCAs $\mathrm{F}^{14} \mathrm{C}$ values, with calculated fossil carbon contributions of 10.1, $30.2,6.9 \%$ for marine sediment, urban dust and riverine NOM, respectively. As such, these carefully corrected molecular ${ }^{14} \mathrm{C}$ data provide a robust benchmark against which to place quantitative constraints on $\mathrm{PyC}$ sources and cycling in the environment. The large differences between the ${ }^{14} \mathrm{C}-\mathrm{BPCA}_{\text {uncorrected }}$ and ${ }^{14} \mathrm{C}$ - $\mathrm{BPCA}_{\text {corrected }}$ (Table 2) clearly highlight the uncertainty that contamination can introduce with respect to $\mathrm{PyC}$ source apportionment. 
Even though the extent to which contamination affects the result is mass dependent, an accurate $\mathrm{F}^{14} \mathrm{C}$ signature of the contaminant is nevertheless required to make the correct adjustment. An interpretation of molecular ${ }^{14} \mathrm{C}$ data of combustion products without a correction for extraneous carbon could lead to either under- or overestimating different pools of $\mathrm{PyC}$ in samples. The need for accurate and precise data is particularly high for the validation of numerical models that mimic PyC pools and fluxes in the global environment. Currently, the extrapolation of our results to the global scale is limited by the lack of available quantitative and qualitative data, particularly in sediments (Bird et al. 2015) as well as by the high uncertainty (often larger than two orders of magnitude) in modeling the global pyrogenic carbon cycle (Landry and Matthews 2016). Here, the thoroughly corrected empirical ${ }^{14} \mathrm{C}$ data can serve as a reference to better constrain and validate models in future attempts.

In archaeology, visually distinct charcoal particles are commonly picked by hand (e.g., with the aid of an optical microscope) and used for ${ }^{14} \mathrm{C}$ dating. Here, measurement and comprehensive correction of BPCA ${ }^{14} \mathrm{C}$ data opens up the possibility of investigating matrices where charred residues are present as submicroscopic finely disseminated particles that would not be amenable to conventional approaches.

With respect to applications of ${ }^{14} \mathrm{C}$-BPCA for the purpose of apportioning sources of combustion residues, calculations using the end member model of $\mathrm{F}^{14} \mathrm{C}_{\text {depleted }}$ and $\mathrm{F}^{14} \mathrm{C}_{\text {modern }}$ reveal that the two different scenarios for modern $\mathrm{F}^{14} \mathrm{C}$ (contemporary vs. biomass) have a lesser impact $(15.2 \%$ in sediment, $1.4 \%$ in urban dust, $7.6 \%$ in riverine NOM) compared to the correction of measured data for extraneous carbon (6.9 to $30.2 \%$, as discussed above). This important observation strengthens the concept of source apportionment based on thoroughly corrected ${ }^{14} \mathrm{C}$ data. In this study, we only used reference materials (surface deposits) collected post-1950s and thus the modern $\mathrm{F}^{14} \mathrm{C}$ end member should reflect the high atmospheric

${ }^{14} \mathrm{C}$ concentrations during the assimilation of carbon into biomass. This period of time might serve as an extreme case to test this concept of source apportionment and suggests an even lower susceptibility for samples predating this time period. Constraining the actual contemporary $\mathrm{F}^{14} \mathrm{C}$ of feedstock materials in natural environments may prove challenging but fortunately it appears to be not imperative for the robust apportionment of PyC sources. Instead, differences in source areas (proximal versus distal), mode of transport (e.g, runoff versus atmospheric deposition), predepositional histories (e.g, temporary storage in soils) are likely to result in greater sources of uncertainty in apportioning PyC derived from fossil fuels and biomass.

\section{CONCLUSIONS}

Comprehensive quantification and isotopic characterization of extraneous carbon was achieved via use of multiple process standards that encompass each of the four subprocedures applied in BPCA ${ }^{14} \mathrm{C}$ analysis: (1) oxidative degradation of condensed aromatics, (2) BPCA isolation by $\mathrm{LC}_{\text {prep }}$, (3) wet chemical oxidation (WCO) of purified BPCAs, and (4) the subsequent measurement of resulting $\mathrm{CO}_{2}$ using a gas ion source-equipped AMS. Each subprocedure introduced some extraneous carbon, with the highest proportion determined to stem from the $W C O$ step. Despite the significant extraneous carbon associated with this procedure, the ease and rapidity of WCO carries considerable advantages, enabling high-throughput, lower cost processing of standards and samples that ultimately yield more comprehensive BPCAs ${ }^{14} \mathrm{C}$ datasets.

The comprehensive assessment of (and correction for) contamination coupled with triplicate analyses of BPCAs isolated from four standard reference samples encompassing a range of 
complex environmental matrices yielded robust ${ }^{14} \mathrm{C}$ values that provide new isotopic benchmarks for these reference materials. To fully exploit the potential of CSRA on pyrogenic carbon, particularly with respect to ${ }^{14} \mathrm{C}$ dating applications, the methodological protocol should include process standards, each encompassing end-members in ${ }^{14} \mathrm{C}$ natural abundance and spanning an equivalent concentration range to that of the target analytes. Following such comprehensive assessment of extraneous carbon, BPCAs ${ }^{14} \mathrm{C}$ can serve as a versatile tool for improving our understanding of fate and residence time of combustion products in the environment.

\section{ACKNOWLEDGMENTS}

We thank Simon Fahrni (Ionplus AG, Switzerland) for his kind on-call help with the AMS outside regular work hours. Michael Hilf and Guido Wiesenberg (University of Zurich, UZH, Switzerland) kept the preparative LC in good repair. We acknowledge Philippa Ascough and Michael Bird for providing us the archeological ${ }^{14} \mathrm{C}$-depleted charcoal (MA), we appreciate the many helpful discussions on preparative chromatography with Daniel Montluçon (ETH Zürich, Switzerland) and Daniel Wiedemeier (UZH).

\section{SUPPLEMENTARY MATERIAL}

To view supplementary material for this article, please visit https://doi.org/10.1017/ RDC.2017.44

\section{REFERENCES}

Alloway BV, Pribadi A, Westgate JA, Bird MI, Fifield LK, Hogg A, Smith I. 2004. Correspondence between glass-FT and ${ }^{14} \mathrm{C}$ ages of silicic pyroclastic flow deposits sourced from Maninjau caldera, west-central Sumatra. Earth and Planetary Science Letters 227(1-2):121-33. doi: 10.1016/ j.epsl.2004.08.014.

Armstrong FAJ, Williams PM, Strickland JDH. 1966. Photo-oxidation of organic matter in sea water by ultra-violet radiation, analytical and other applications. Nature 211(5048):481-3. doi: 10.1038/ $211481 \mathrm{a} 0$.

Beaupré SR, Druffel ERM, Griffin S. 2007. A low-blank photochemical extraction system for concentration and isotopic analyses of marine dissolved organic matter. Limnology and Oceanography: Methods 5(6):174-84. doi: 10.4319/lom. 2007.5.174.

Bird MI, Wynn JG, Saiz G, Wurster CM, McBeath AV. 2015. The pyrogenic carbon cycle. Annual Review of Earth and Planetary Sciences 43:273-98. doi: 10.1146/annurev-earth-060614105038 .

Blumer M. 1976. Polycyclic aromatic compounds in nature. Scientific American 234(3):34-45. doi: 10.1038/scientificamerican0376-34.

Blumer M, Youngblood WW. 1975. Polycyclic aromatic hydrocarbons in soils and recent sediments. Science 188(4183):53-5. doi: 10.1126/science. 188. 4183.53.

Boutton TW, Wong WW, Hachey DL, Lee LS, Cabrera MP, Klein PD. 1983. Comparison of quartz and pyrex tubes for combustion of organic samples for stable carbon isotope analysis. Analytical Chemistry 55(11):1832-3. doi: 10.1021/ ac00261a049.

Carcaillet C. 2001. Soil particles reworking evidences by AMS ${ }^{14} \mathrm{C}$ dating of charcoal. Comptes Rendus de l'Académie des Sciences - Series IIA - Earth and Planetary Science 332(1):21-8. doi: 10.1016/ S1251-8050(00)01485-3.

Coppola AI, Ziolkowski LA, Druffel ERM. 2013. Extraneous carbon assessments in radiocarbon measurements of black carbon in environmental matrices. Radiocarbon 55(2-3):1631-40. doi: 10.2458/ azu_js_rc.55.16303.

Coppola AI, Walker BD, Druffel ERM. 2015. Solid phase extraction method for the study of black carbon cycling in dissolved organic matter using radiocarbon. Marine Chemistry 177(5):697-705. doi: 10.1016/j.marchem.2015.10.010.

Currie LA. 2000. Evolution and multidisciplinary frontiers of ${ }^{14} \mathrm{C}$ aerosol science. Radiocarbon 42(1): 115-26. doi: 10.1017/S003382220005308X.

Currie LA, et al. 2002. A critical evaluation of interlaboratory data on total, elemental, isotopic carbon in the carbonaceous particle reference material, NIST SRM 1649a. Journal of Research of the National Institute of Standards and Technology 107(3):279-98.

Currie LA, Murphy RB. 1977. Origin and residence times of atmospheric pollutants: application of ${ }^{14}$ C. National Bureau of Standards Special Publication 464:439-47. 
Currie LA, Stafford TW, Sheffield AE, Klouda GA, Wise SA, Fletcher RA, Donahue DJ, Jull AJT, Linick TW. 1989. Microchemical and molecular dating. Radiocarbon 31(3):448-63. doi: 10.2458/ azu_js_rc.31.1171.

Dittmar T. 2008. The molecular level determination of black carbon in marine dissolved organic matter. Organic Geochemistry 39(4):396-407. doi: 10.1016/j.orggeochem.2008.01.015.

Fahrni SM, Wacker L, Synal HA, Szidat S. 2013. Improving a gas ion source for ${ }^{14} \mathrm{C}$ AMS. Nuclear Instruments and Methods in Physics Research B 294:320-7. doi: 10.1016/j.nimb.2012.03.037.

Gierga M, Schneider MPW, Wiedemeier DB, Lang SQ, Smittenberg RH, Hadjas I, Bernasconi SM, Schmidt MWI. 2014. Purification of fire derived markers for $\mu \mathrm{g}$ scale isotope analysis $\left(\delta^{13} \mathrm{C}, \Delta^{14} \mathrm{C}\right)$ using high performance liquid chromatography (HPLC). Organic Geochemistry 70(1): 1-9. doi: 10.1016/j.orggeochem.2014.02.008.

Glaser B, Haumeier L, Guggenberger G, Zech W. 1998. Black carbon in soils: the use of benzenecarboxylic acids as specific markers. Organic Geochemistry 29(4):811-9. doi: 10.1016/S01466380(98)00194-6.

Gustafsson Ö, Bucheli TD, Kukulska Z, Andersson M, Largeau C, Rouzaud JN, Reddy CM, Eglinton TI. 2001. Evaluation of a protocol for the quantification of black carbon in sediments. Global Biogeochemical Cycles 15(4):881-90. doi: 10.1029/ $2000 \mathrm{gb} 001380$.

Gustafsson Ö, Gschwend PM. 1997. Soot as a strong partition medium for polycyclic aromatic hydrocarbons in aquatic systems. ACS Symposium Series 671:365-81.

Hammes K, Smernik R, Skjemstad JO, Herzog A, Vogt UF, Schmidt MWI. 2006. Synthesis and characterisation of laboratory-charred grass straw (Oryza sativa) and chestnut wood (Castanea sativa) as reference materials for black carbon quantification. Organic Geochemistry 37(11):1629-33. doi: 10.1016/j.orggeochem.2006.07.003.

Hammes K, Smernik R, Skjemstad JO, Schmidt MWI. 2008. Characterisation and evaluation of reference materials for black carbon analysis using elemental composition, colour, BET surface area and ${ }^{13} \mathrm{C}$ NMR spectroscopy. Applied Geochemistry 23(8):2113-22. doi: 10.1016/j.apgeochem.2008. 04.023 .

Hanke UM, Eglinton TI, Braun ALL, Reddy CM, Wiedemeier DB, Schmidt MWI. 2016. Decoupled sedimentary records of combustion: causes and implications. Geophysical Research Letters 43(10): 5098-108. doi: 10.1002/2016GL069253.

Hedges JI, et al. 2000. The molecularlyuncharacterized component of nonliving organic matter in natural environments. Organic Geochemistry 31(10):945-58. doi: 10.1016/S0146-6380 (00)00096-6.

Hwang J, Druffel ERM. 2008. Blank correction for delta- ${ }^{14} \mathrm{C}$ measurements in organic compound classes of oceanic particulate matter. Radiocarbon 47(1):75-87. doi: 10.2458/azu_js_rc.47.2802.

Kirner DL, Taylor RE, Southon JR. 1995. Reduction in backgrounds of microsamples for AMS ${ }^{14} \mathrm{C}$ dating. Radiocarbon 37(2):697-704. doi: 10.2458/azu_js_rc.37.1722.

Landry J-S, Matthews HD. 2016. The global pyrogenic carbon cycle and its impact on the level of atmospheric $\mathrm{CO}_{2}$, over past and future centuries. Global Change Biology. doi: 10.1111/ gcb. 13603.

Lang SQ, Früh-Green GL, Bernasconi SM, Wacker L. 2013. Isotopic (delta ${ }^{13} \mathrm{C}$, Delta ${ }^{14} \mathrm{C}$ ) analysis of organic acids in marine samples using wet chemical oxidation. Limnology and Oceanography-Methods 11:161-75. doi: 10.43 19/lom.2013.11.161.

Lang SQ, McIntyre CP, Bernasconi SM, FrühGreen GL, Voss BM, Eglinton TI, Wacker L. 2016. Rapid ${ }^{14} \mathrm{C}$ analysis of dissolved organic carbon in non-saline waters. Radiocarbon 58(3): 505-15. doi:dx.doi.org/ 10.1017/RDC.2016.17.

Leonard A, Castle S, Burr GS, Lange T, Thomas J. 2013. A wet oxidation method for AMS radiocarbon analysis of dissolved organic carbon in water. Radiocarbon 55(2-3):545-52. doi: 10.2458/ $\mathrm{azu}$ js_rc.55.16277.

Levin I, Kromer B. 2004. The tropospheric ${ }^{14} \mathrm{CO}_{2}$ level in mid latitudes of the Northern Hemisphere. Radiocarbon 46(3):1261-72. doi: 10.1017/S00338 22200033130.

Levin I, Kromer B, Hammer S. 2013. Atmospheric $\mathrm{D}^{14} \mathrm{CO}_{2}$ trend in Western European background air from 2000 to 2012. Tellus B 65(20092). doi: 10.3402/tellusb.v65i0.20092.

Lewis CW, Klouda GA, Ellenson WD. 2004. Radiocarbon measurement of the biogenic contribution to summertime PM-2.5 ambient aerosol in Nashville, TN. Atmospheric Environment 38: 6053-61. doi: 10.1016/j.atmosenv.2004.06.011.

Lima AL, Farrington JW, Reddy CM. 2005. Combustion-derived polycyclic aromatic hydrocarbons in the environment - a review. Environmental Forensics 6(2):109-31. doi: 10.1080/ 15275920590952739.

Mann PJ, Eglinton TI, McIntyre CP, Zimov N, Davydova A, Vonk JE, Holmes RM, Spencer RGM. 2015. Utilization of ancient permafrost carbon in headwaters of Arctic fluvial networks. Nature Communications 6:7856. doi: 10.1038/ ncomms8856.

Masiello CA, Druffel ERM, Currie LA. 2002. Radiocarbon measurements of black carbon in aerosols and ocean sediments. Geochimica et Cosmochimica Acta 66(6):1025-36. doi: 10.1016/ S0016-7037(01)00831-6.

McNichol AP, Aluwihare LI. 2007. The power of radiocarbon in biogeochemical studies of the marine carbon cycle: insights from studies of dissolved and particulate organic carbon (DOC and POC). Chemical Reviews 107(2):443-66. doi: $10.1021 / \mathrm{cr} 050374 \mathrm{~g}$. 
Meredith W, Ascough PL, Bird MI, Large DJ, Snape CE, Sun Y, Tilston EL. 2012. Assessment of hydropyrolysis as a method for the quantification of black carbon using standard reference materials. Geochimica et Cosmochimica Acta 97:131-47. doi: 10.1016/j.gca.2012.08.037.

Mollenhauer G, Rethemeyer J. 2009. Compoundspecific radiocarbon analysis - analytical challenges and applications. IOP Confererence Series: Earth and Environmental Science. 5. doi: 10.1088/17551307/5/1/012006.

NIST. 2007. Certificate of Analysis Standard Reference Material 1649a. National Institute of Standards and Technology.

NIST. 2015. Certificate of Analysis Standard Reference Material 1941b. National Institute of Standards and Technology.

Pearson A, McNichol AP, Schneider RJ, von Reden KF, Zheng Y. 1998. Microscale AMS ${ }^{14} \mathrm{C}$ measurement at NOSAMS. Radiocarbon 40(1): 61-75. doi: 10.2458/azu_js_rc.40 1989.

Reddy CM, Pearson A, Xu L, McNichol AP, Benner BA Jr, Wise SA, Klouda GA, Currie LA, Eglinton TI. 2002. Radiocarbon as a tool to apportion the sources of polycyclic aromatic hydrocarbons and black carbon in environmental samples. Environmental Science \& Technology 36(8): 1774-82. doi: 10.1021/es011343f.

Reimer PJ, Brown TA, Reimer RW. 2004. Discussion: reporting and calibration of post-bomb ${ }^{14} \mathrm{C}$ data. Radiocarbon 46(3):1299-304. doi: 10.2458/ azu_js_rc.46.4183.

Roth PJ, Lehndorff E, Brodowski S, Bornemann L, Sánchez-García L, Gustafsson Ö, Amelung W. 2012. Differentiation of charcoal, soot, diagenetic carbon in soil: method comparison and perspectives. Organic Geochemistry 46:66-75. doi: 10.1016/j.orggeochem.2012.01.012.

Santos GM, Southon JR, Drenzek NJ, Ziolkowski LA, Druffel ERM, Xu X, Zhang D, Trumbore SE, Eglinton TI, Hughen KA. 2010. Blank assessment for ultra-small radiocarbon samples: chemical extraction and separation versus AMS. Radiocarbon 52(2-3):1322-35. doi: 10.2458/azu_js_rc. 52.3631 .

Schneider MPW, Smittenberg RH, Dittmar T, Schmidt MWI. 2011. Comparison of gas with liquid chromatography for the determination of benzenepolycarboxylic acids as molecular tracers of black carbon. Organic Geochemistry 42(3): 275-82. doi: 10.1016/j.orggeochem.2011.01.003.
Shah SR, Pearson A. 2007. Ultra-microscale $\left(5-25 \mu \mathrm{g}\right.$ C) analysis of individual lipids by ${ }^{14} \mathrm{C}$ AMS: Assessment and correction for sample processing blanks. Radiocarbon 49(1):69-82. doi: 10.1017/S0033822200041904.

Szidat S, Jenk TM, Synal HA, Kalberer M, Wacker L, Hajdas I, Kasper-Giebl A, Baltensperger U. 2006. Contributions of fossil fuel, biomass burning, biogenic emissions to carbonaceous aerosols in Zurich as traced by ${ }^{14} \mathrm{C}$. Journal of Geophysical Research 111(D7):1-12. doi: 10.1029/2005JD006590.

Trumbore SE. 2009. Radiocarbon and soil carbon dynamics. Annual Review of Earth and Planetary Sciences 37:47-66. doi: 10.1146/annurev. earth.36.031207.124300.

Van der Voort TS, Hagedorn F, McIntyre CP, Zell C, Walthert L, Schleppi P, Feng X, Eglinton TI. 2016. Variability in ${ }^{14} \mathrm{C}$ contents of soil organic matter at the plot and regional scale across climatic and geologic gradients. Biogeosciences 13:3427-39. doi: 10.5 194/bg-13-3427-2016.

Wacker L, Christl M. 2012. Data reduction for small radiocarbon samples - error propagation using the model of constant contamination. ETH Zürich Laboratory of Ion Beam Physics: Annual Report 2011.

Wacker L, Christl M, Synal HA. 2010. Bats: a new tool for AMS data reduction. Nuclear Instruments and Methods in Physics Research B 268(7-8): 976-9. doi: 10.1016/j.nimb.2009.10.078.

Wacker L, Fahrni SM, Hajdas I, Molnar M, Synal HA, Szidat S, Zhang YL. 2013. A versatile gas interface for routine radiocarbon analysis with a gas ion source. Nuclear Instruments and Methods in Physics Research B 294:315-9. doi: 10.1016/ j.nimb.2012.02.009.

Wiedemeier DB, et al. 2016. Characterization, quantification and compound-specific isotopic analysis of pyrogenic carbon using benzene polycarboxylic acids (BPCA). Journal of Visualized Experiments. 111. doi: $10.3791 / 53922$.

Xu L, Zheng M, Ding X, Edgerton ES, Reddy CM. 2012. Modern and fossil contributions to polycyclic aromatic hydrocarbons in PM2.5 from North Birmingham, Alabama in the Southeastern U.S. Environmental Science \& Technology 46(3): 1422-9. doi: 10.1021/es2043189.

Ziolkowski LA, Druffel ERM. 2009. Quantification of extraneous carbon during compound-specific radiocarbon analysis of black carbon. Analytical Chemistry 81(24):10156-61. doi: 10.1021/ac901922s. 